\title{
Management of Countertransference with Borderline Patients
}

\author{
Jaehyun Han \\ Department of Psychiatry, Yonsei University Wonju College of Medicine, Wonju, Korea
}

\section{역전이와 경계선 환자의 치료}

\section{한재현}

연세대학교 원주의과대학 정신건강의학교실

저 자: Glen O. Gabbard, Sallye M. Wilkinson

출판사: American Psychiatric Press, Inc.

출간연도: 1994 (ISBN: 978-0880485630)

\section{서 론}

이 책은 1994년에 처음 출판되었다. Gabbard와 Wilkinson 은 1991년 Annual Meeting of American Psychiatric Association에서 경계선 환자와 역전이에 대한 발표를 한 후, 경 계선 환자와의 치료에서 상처를 받은 많은 청중들의 반응을 보고 이 책을 쓰기로 결심했다. 즉, 이 책은 경계선 환자를 치 료할 때 마주할 수밖에 없는 거대한 역전이의 소용돌이 속에 서 길을 잃은 치료자를 위하여 쓰였다.

이 책은 벼랑 끝에 몰린 것 같은 위태위태한 치료자에게 그 순간이 오히려 환자를 이해하고 환자를 도와줄 수 있는 중요한 순간이라는 것을 알려주고자 한다. Thomas H. Ogden, Christopher Bollas, Harold F. Searles이 서평에서 공통 적으로 언급했듯, 이 책은 많은 임상 장면에 대한 생생한 묘 사를 담고 있으며, 저자들은 자신들이 느낀 역전이에 대해 놀랄 만큼 정직하게 서술함으로써 경계선 환자를 치료하기

Address for correspondence: Jaehyun Han, MD

Department of Psychiatry, Yonsei University Wonju College of Medicine, 20 Ilsan-ro, Wonju 26426, Korea

Tel: +82-33-741-1260, Fax: +82-33-741-0532

E-mail: jhan0805@yonsei.ac.kr

This is an Open Access article distributed under the terms of the Creative Commons Attribution Non-Commercial License (https://creativecommons.org/licenses/by-nc/4.0) which permits unrestricted non-commercial use, distribution, and reproduction in any medium, provided the original work is properly cited.
위해 분투하는 치료자에게 깊은 위로와 지혜를 전달한다. 마 치 이 책은 경계선 환자와의 치료경험에 대한 이해를 통해 one person psychology에서 two person psychology로 넘어 가는 다리를 건설하려는 것처럼 보인다.

\section{치료실 내의 두 명의 환자: 상연에 대한 개념화}

현대 정신분석은 '무엇이 환자를 변화시키는가'에 대한 논 의에서 치료적 '관계'의 중요성을 강조하고 있으며, '관계'의 경험은 이제 '해석'만큼 중요한 역할을 하는 것으로 여겨지 고 있다. 그리고 이때의 '관계' 경험의 핵심은 환자가 사용하 는 투사적 동일시에 대한 치료자의 대응으로 요약할 수 있 다. 이 책은 투사적 동일시에 대한 역사적 고찰을 통해 치료 자와 환자 사이의 상호작용을 세밀하게 분석해간다. 그리고 치료 중에 발생하는 관계의 경험을 모두 환자로부터 투사된 것으로 여기고 모든 책임을 환자에게 돌리지 않기 위해, 또 한 관계에 대한 치료자의 역할을 지나치게 강조함으로써 치 료자에게 너무 큰 짐을 지우지 않기 위해, 이 책은 '치료실 내에 두 명의 환자가 있다'는 개념을 소개하고 있다. 저자들 은 투사적 동일시와 이로 인한 상연이 치료자와 환자 중 어 느 한쪽의 기여만으로는 설명되지 않으며, 치료자와 환자가 함께 만들어내는 공동의 산물(joint creation)이라는 입장을 취한다. 치료자의 마음 안에 환자의 투사에 반응할 만한 부 분이 이미 존재하며 그 부분이 환자의 투사에 공명하는 것 이 투사적 동일시의 본질일 것이라고 설명하고 있다. 치료자 입장에서는 치료자 역시 상연에 기여하고 있다는 점을 받아 들이는 것이 어려울 수 있지만, 이 시각은 치료자로 하여금 소용돌이 치는 역전이 속에서 자신의 기여를 발견하고 이해 
하는 노력을 시도하도록 만들며, 이는 치료자가 '자기분석' 을 통해 치료자로서의 자기 자리를 되찾도록 돕는다.

\section{경계선 환자와의 치료에서 겪는 역전이}

모든 치료과정에서 역전이와 상연은 필연적으로 발생하 지만, 경계선 환자와의 치료에서는 치료자의 역할이 위협될 정도로 높은 강도의 역전이와 위험한 수준의 상연이 발생할 수 있다. 이 책에서는 경계선 환자와의 작업에서 발생하는 높은 강도의 전이-역전이 현상이 환자의 경험에 대해 상징 적으로 작업할 수 있는 분석적 공간의 붕괴로 인해 발생한 다고 설명한다. 경계선 환자는 전이의 '마치 인 것 같은(as if)' 측면을 이해하지 못하기 때문에 치료자에게도 실제에 가 까운 강렬한 역전이를 일으키고, 동시에 이에 대해 상징적으 로 작업할 만한 치료자의 능력을 마비시킨다. 경계선 환자는 치료자를 부모처럼 경험하는 것이 아니라 '실제 부모'가 되어 주기를 바라며, 실제로 경험되는 강력한 의존 소망은 치료자 에게 죄책감, 구원 환상, 분노와 증오, 무력감과 무가치함, 불 안과 공포를 느끼도록 만들고 직업적 경계의 이탈을 일으킬 수 있다. 이러한 상황 속에서 치료자는 그동안 자신이 유지해 오던 고유의 생각방식을 잃어버리고 무수한 감정 속에 휩싸 이게 되는데, 저자들은 이러한 일이 경계선 환자와의 치료에 서는 매우 자연스럽고 당연하다는 점을 강조했다. 그리고 이 때 치료자의 역할은 붕괴된 분석적 공간을 비집어 열어서 환 자와 함께 환자의 경험에 대한 상징적인 작업을 할 수 있도록 하는 데 있다고 제안한다.

\section{역전이에 대한 치료자의 대응}

이 책에서는 '반응(react)'와 '대응(response)'의 구분을 통 해 강렬한 역전이를 다루는 방법의 핵심을 알기 쉽게 소개하 고 있다. 저자들은 역전이 반응을 무릎 반사에 비유한 후, 치 료자는 무릎 반사처럼 자동적이고 반사적으로 일어나는 "반 응'을 피해야 하며, 자극에 대해 지각하고 숙고 후 '대응'해야 한다는 점을 강조한다. 또한 어느 정도 '반응'이 일어나는 것 은 피할 수 없는 일이며, 반응이 일어난 후 이를 헤아려보는 과정을 통해 '대응'할 수 있는 능력을 키우는 것이 중요하다 고 썼다. 이 비유는 치료자가 안아주기 환경(holding environment)을 제공하고 담아내는 역할(containing)을 하는 것 을 무조건적인 수용이나 무한의 인내로 오해하지 않도록 돕 는다. 경계선 환자와의 치료는 너무 가까워져서 융합될 것 같은 공포와 너무 멀어져서 버려질 것 같은 위험 사이를 진 동하며 환자와 함께 최적의 거리를 형성해 가는 과정으로,
이러한 환자의 절박한 시도에 반응하지 않고 대응하려는 치 료자의 노력이 필요하다. 또한 환자를 변화시키고 성장하기 위해서는 좌절 혹은 환멸이 필수적이며, 안아주기와 담아내 기 또한 환자에게 성장을 위한 환경을 제공해주면서도 적절 한 좌절과 환멸을 일으키고 이를 함께 애도하기 위한 것으 로 이해되어야 한다. 저자들은 안아주기와 담아내기를 '조용 한 해석'으로 표현함으로써 치료실 내에서 '해석'과 '관계 경 험'이 서로 대립적인 것이 아닌, 환자의 변화에 필수적인 공 통의 치료적 요소임을 보여준다.

\section{역전이를 다룰 때 주의가 필요한 주제들}

경계선 환자와의 치료과정 중 치료자는 많은 딜레마를 마 주하게 되며, 이 책은 그런 순간에 치료자가 반응하지 않고 대응하기 위해 생각해볼 수 있는 내용을 함께 담고 있다. 저 자들은 경계위반의 문제, 치료자의 자기 노출, 성별에 관련 된 주제, 치료자의 임신, 지도감독과 자문, 입원환경에서의 분열에 대해 현실감이 넘치는 경험담을 서술함으로써 실제 치료에서 필요한 실용적이고 유익한 주제들을 전달한다. 저 자들은 치료과정 속에서 수많은 선택의 순간마다 치료자가 생각해 보아야하는 두 가지 질문을 소개한다. 먼저 치료자는 자신의 대응이 환자를 돕기 위한 것인지 아니면 자신의 역전 이를 줄이기 위한 것인지를 자신에게 질문해보아야 한다. 또 한 치료자는 자신의 대응이 환자가 가진 성장에 대한 욕구 (growth needs)를 만족시켜 환자를 성장시킬 것인지, 그렇지 않으면 환자의 리비도적 요구(libidinal demands)만을 충족 시켜 환자를 퇴행시킬 것인지를 고민해보아야 한다. 이 두 가지 질문은 치료자가 자신의 대응을 돌아보고 딜레마 속에 서 치료가 파괴되는 것에 자신도 모르게 공모하지 않을 수 있도록 돕는다.

\section{결 론}

〈역전이와 경계선 환자의 치료〉는 역전이 속에서 고군분 투하며 경계선 환자를 돕고자 애쓰는 치료자를 위로하고 방 향을 잃지 않도록 돕는 지침서에 가깝다. 그렇지만 이 책은 역전이를 다룸으로써 환자를 변화시키는 법을 제안하고 있 지는 않다. 이 책은 오히려 환자를 변화시키려는 지나친 치 료적 열정이 오히려 치료를 위험에 빠뜨릴 가능성이 높다고 지적한다. 그리고 이 책에서는 환자를 변화시키려 하기보다 이해하려고 노력하기를 제안한다. 역전이를 다룬다는 것은 역전이를 들여다봄으로써 자신과 환자를 이해해가는 과정 이며, 그 이해를 통해 치료자와 환자가 함께 성장해가는 과 
정으로 이해될 수 있다.

경계선 환자와의 치료작업에서는 휘몰아치는 급류에 휩쓸 리고 벼랑 끝까지 몰리는 일이 자주 일어난다. 이 책의 저자 들은 바로 그 순간에 이르러서야 치료자는 비로소 환자가 평 생을 안고 살아온 고통스러운 감정들을 함께 공유할 수 있을 지도 모른다고 이야기한다. 그리고 저자들은 경계선 환자를 도우려다가 벼랑 끝에 몰린 치료자에게 묻는다. 만약 환자가 그런 순간에 치료자가 느끼는 고통스럽고 위태한 감정 속에 서 오랫동안 살아왔다고 한다면, 그리고 그 고통을 그 순간
에 치료자가 견디지 못한다면, 과연 환자에게 그 고통을 견 디라고 이야기할 수 있을까? 아마도 저자 자신들을 향했을 이 질문은 이 책을 읽는 치료자의 마음에 오랫동안 남아서 치료자의 마음을 다잡게 할 것이다.

역전이를 능숙하게 다루게 된다면 경계선 환자를 치료할 수 있을까? 저자들은 책의 마지막 장에서 '치료적 무기수’에 대해 적었다. 경계선 환자와의 치료는 끝나지 않고 계속될 수도 있다. 그리고 이를 담담하게 이를 받아들이는 것이 역 전이를 다루기의 마지막 측면이다. 